\title{
Milligram per Kilogram per Dose
}

National Cancer Institute

\section{Source}

National Cancer Institute. Milligram per Kilogram per Dose. NCI Thesaurus. Code C124458.

A dose calculation unit expressed in milligram(s) per kilogram per single dose. 